\title{
Could hemophagocytic lymphohistiocytosis be the core issue of severe COVID-19 cases?
}

\author{
Violetta Opoka-Winiarska ${ }^{1 *}$ D, Ewelina Grywalska ${ }^{2,3}$ (D) and Jacek Roliński ${ }^{2,3}$ (D)
}

\begin{abstract}
Background: COVID-19, a disease caused by the severe acute respiratory syndrome coronavirus 2 (SARS-CoV-2), commonly presents as fever, cough, dyspnea, and myalgia or fatigue. Although the majority of patients with COVID-19 have mild symptoms, some are more prone to serious outcomes, including pneumonia, acute respiratory distress syndrome (ARDS), and even death. Hemophagocytic lymphohistiocytosis (HLH) is a severe, life-threatening inflammatory syndrome associated with intense cytokine release (also known as a "cytokine storm"). Similar to COVID-19, HLH is characterized by aggressive course leading to multi-organ failure.

Main text: The purpose of this review article is to draw attention to the possibility of the complication of HLH in patients with the severe course of COVID-19. Indeed, some of the clinical characteristics observed in the more severe cases of COVID-19 are reminiscent of secondary HLH (which can be triggered by infections, malignancies, rheumatological diseases, or autoimmune/immunodeficiency conditions). The pathogenesis of SARS-CoV-2 infection also suggests that $\mathrm{HLH}$ or a similar hyperinflammatory syndrome is the cause of the severe course of the infection.

Conclusion: The pathogenesis and clinical symptoms of severe COVID-19 indicate that an increased inflammatory response corresponding to HLH is occurring. Therefore, patients with severe COVID-19 should be screened for hyperinflammation using standard laboratory tests to identify those for whom immunosuppressive therapy may improve outcomes.
\end{abstract}

Keywords: Coronavirus, Coronavirus disease 2019, Hemophagocytic lymphohistiocytosis

\section{Background}

An acute infectious disease caused by the severe acute respiratory syndrome coronavirus 2 (SARS-CoV-2), named the coronavirus disease 2019 (COVID-19), presents an imminent public health threat worldwide. As of the 23rd of June 2020, over 8.8 million cases of COVID19 have been confirmed worldwide, and the total number of deaths has surpassed 460,000 [1]. Recent reports have summarized the clinical presentation of COVID-19, which commonly presents as fever, cough, dyspnea, and

\footnotetext{
* Correspondence: violetta.opoka-winiarska@umlub.pl

'Department of Paediatric Pulmonology and Rheumatology, Medical University of Lublin, Gębali 6, 20-093 Lublin, Poland

Full list of author information is available at the end of the article
}

myalgia or fatigue [2-8]. Although the majority of patients with COVID-19 have mild symptoms, some patients (especially those with underlying diseases) are more prone to serious outcomes, including pneumonia, acute respiratory distress syndrome (ARDS), and even death $[9,10]$. Current research efforts are focused on identifying the cause of the aggressive course of the disease and the high mortality rates observed with severe COVID-19, as well as developing novel therapies [10].

Some of the clinical characteristics observed in the more severe cases of COVID-19 [6-8] are reminiscent of hemophagocytic lymphohistiocytosis (HLH), a severe, life-threatening inflammatory syndrome associated with intense cytokine release (also known as a "cytokine

(c) The Author(s). 2020 Open Access This article is licensed under a Creative Commons Attribution 4.0 International License, which permits use, sharing, adaptation, distribution and reproduction in any medium or format, as long as you give appropriate credit to the original author(s) and the source, provide a link to the Creative Commons licence, and indicate if changes were made. The images or other third party material in this article are included in the article's Creative Commons licence, unless indicated otherwise in a credit line to the material. If material is not included in the article's Creative Commons licence and your intended use is not permitted by statutory regulation or exceeds the permitted use, you will need to obtain permission directly from the copyright holder. To view a copy of this licence, visit http://creativecommons.org/licenses/by/4.0/. The Creative Commons Public Domain Dedication waiver (http://creativecommons.org/publicdomain/zero/1.0/) applies to the data made available in this article, unless otherwise stated in a credit line to the data. 
storm") [11]. HLH is characterized by aggressive course leading to multi-organ failure [12]. As HLH can develop in response to viral infections [12], it may be triggered by SARS-CoV-2, which could explain the rapid disease progression observed in some patients.

This review summarizes the pathogenesis and clinical characteristics of COVID-19 that suggests HLH or a similar hyperinflammatory syndrome is the cause of the severe course of the infection. A timely diagnosis of HLH in patients with COVID-19 would offer new therapeutic strategies (e.g., immunosuppression), which in turn, may reduce the significant mortality rates currently associated with this virus.

\section{Main text}

HLH: an aberrant immune response to viral infections

The majority of viral infections acquired by nonimmunosuppressed individuals are asymptomatic or result in mild clinical manifestations; however, for those who are immunocompromised or have an immune disorder, viral infections may result in a life-threatening disease, as occurs in the case of HLH (Table 1) [13]. In $\mathrm{HLH}$, aberrant activation of $\mathrm{T}$ cells, natural killer (NK) cells, and macrophages causes overproduction of inflammatory cytokines (i.e., the so-called cytokine storm) and hemophagocytosis $[13,14]$. This excessive autoinflammatory response leads to rapidly progressing multiorgan failure [13].

HLH is generally divided into two types: primary or familial HLH (which is observed in pediatric patients) and secondary HLH (sHLH, found also in adults). Primary HLH is caused by genetic defects (e.g., mutations in PRF1 or UNC13D, which are typically involved in the perforin-mediated killing of target cells [11]), while a range of triggers are described for $\mathrm{sHLH}$, including infections, malignancies, rheumatological diseases, or autoimmune/immunodeficiency conditions [13, 15]. EpsteinBarr virus (EBV) and herpes simplex virus (HSV) infections are the most frequent triggers of sHLH, although other viruses (e.g., cytomegalovirus, hepatitis A, parvovirus B19, adenovirus, influenza) and pathogens (e.g., bacteria, fungi, parasites) have also been implicated [1319]. In cases of primary HLH, several different gene defects can lead to the common phenotype of impaired NK/T cell cytotoxicity [20]. Defects in the function of NK and cytotoxic $T$ cells also lead to excessive inflammation in sHLH, when these cells are activated by an external trigger [20].

\section{The clinical characteristics of COVID-19 resemble sHLH}

The cardinal features of sHLH are high fever, hepatomegaly, splenomegaly, cytopenia (e.g., anemia, thrombocytopenia, and neutropenia), coagulopathy, central nervous system disturbances, and rapidly progressing multi-organ failure [14, 16-19]. Respiratory symptoms, which commonly present as dyspnea and cough, or ARDS can also occur in patients with sHLH. This phenomenon mostly occurs in cases triggered by respiratory viruses, and the signs of infection may overlap with the symptoms of sHLH [21]. Similarly, the majority of patients with COVID-19 present with high fever (observed in $44 \%$ of patients upon presentation, and subsequently, in 64.5-99\% patients), cough (45-82\%), dyspnea (6.5-63.5\%), and myalgia or fatigue (11-70\%) [2-8]. Some patients also show liver damage (transaminase activity), lymphocytopenia, and rapidly progressing multi-organ failure $[9,10,14,16,18]$. Indeed, a number of the cardinal clinical features of these two conditions are shared, as summarized in Table 2.

In terms of laboratory findings, cytopenia is often observed in sHLH, with thrombocytopenia identified in $80-90 \%$ of cases $[14,16,17,19]$. In addition, almost $60 \%$ of patients with HLH have coagulation disorders, while hypofibrinogenemia and raised D-dimer levels are reported in $\sim 40-60 \%$ of HLH cases [14, 18, 19]. Furthermore, $\sim 80 \%$ of patients have altered liver test results (i.e., increased phosphatase alkaline and transaminase concentrations), and increased serum lactate dehydrogenase (LDH) concentrations resulting from cell destruction are reported in $78-92.8 \%$ of patients $[14,16$, 18, 19]. Hypertriglyceridemia (associated with lipoprotein lipase inhibition caused by excess tumor necrosis factor-alpha [TNF- $\alpha]$ ) is found in $\sim 36-71 \%$ of adults with HLH [14, 16, 18, 19]. Increased acute phase

Table 1 Effects of immune status on the course of viral infections, outcomes, and therapy

\begin{tabular}{|c|c|c|c|}
\hline & Normal immunity & $\begin{array}{l}\text { Immunodeficiency (primary or } \\
\text { secondary) }\end{array}$ & Immune disorder (genetic or acquired) \\
\hline $\begin{array}{l}\text { Response to } \\
\text { infection }\end{array}$ & Correct & Insufficient & Excessive \\
\hline $\begin{array}{l}\text { Course of viral } \\
\text { infection }\end{array}$ & $\begin{array}{l}\text { Infection limitation and subsequent } \\
\text { elimination }\end{array}$ & $\begin{array}{l}\text { Disseminated, systemic or chronic viral } \\
\text { infection }\end{array}$ & $\begin{array}{l}\text { Disseminated or systemic inflammation (i.e., } \\
\text { HLH, CRS) }\end{array}$ \\
\hline Consequences & Recovery & Single or multi-organ failure & Multi-organ failure \\
\hline $\begin{array}{l}\text { Potential } \\
\text { interventions }\end{array}$ & $\begin{array}{l}\text { Vaccinations } \\
\text { Antiviral drugs }\end{array}$ & $\begin{array}{l}\text { Vaccinations } \\
\text { Antiviral drugs } \\
\text { Intravenous immunoglobulins }\end{array}$ & Immunosuppression \\
\hline
\end{tabular}




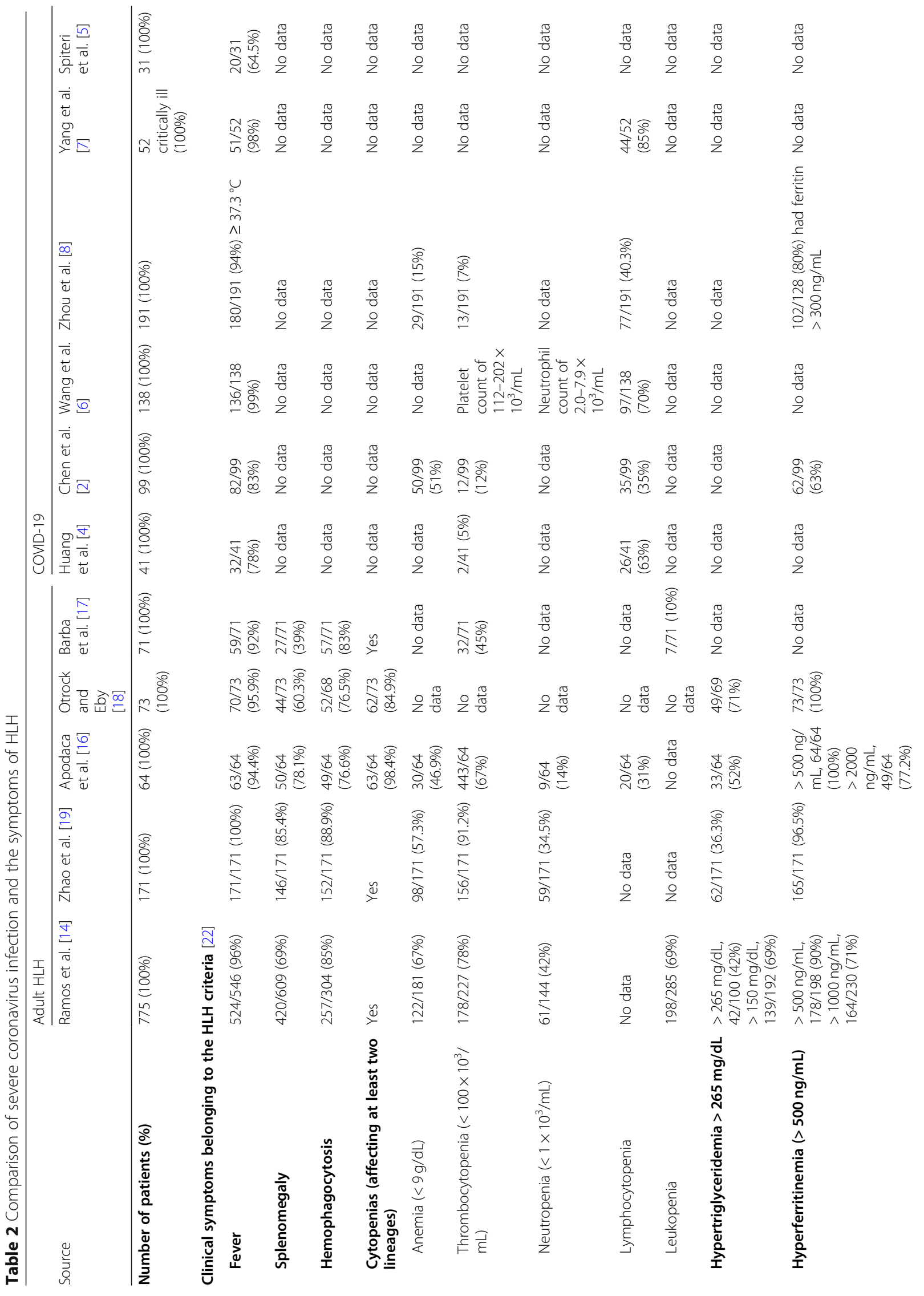




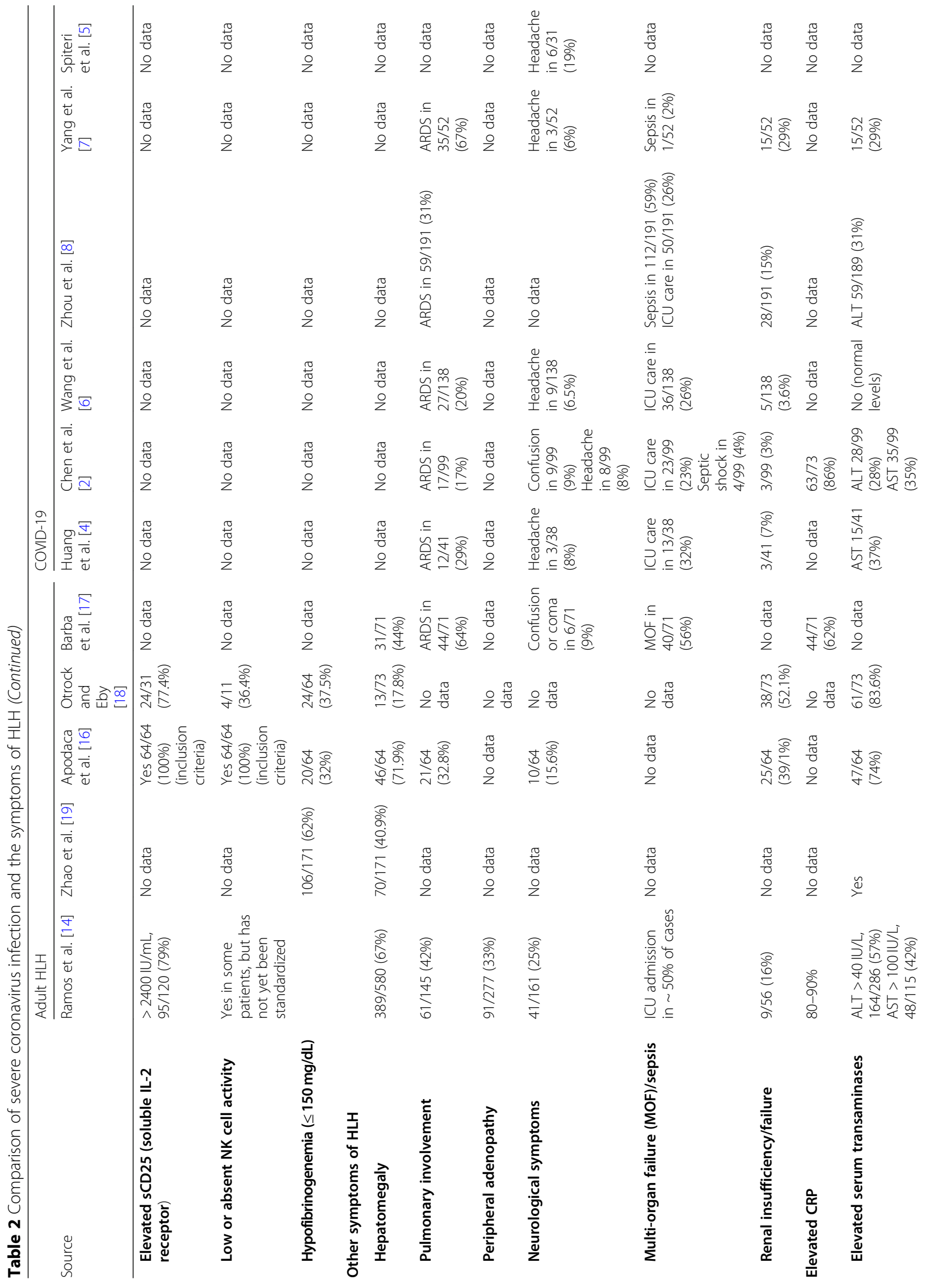




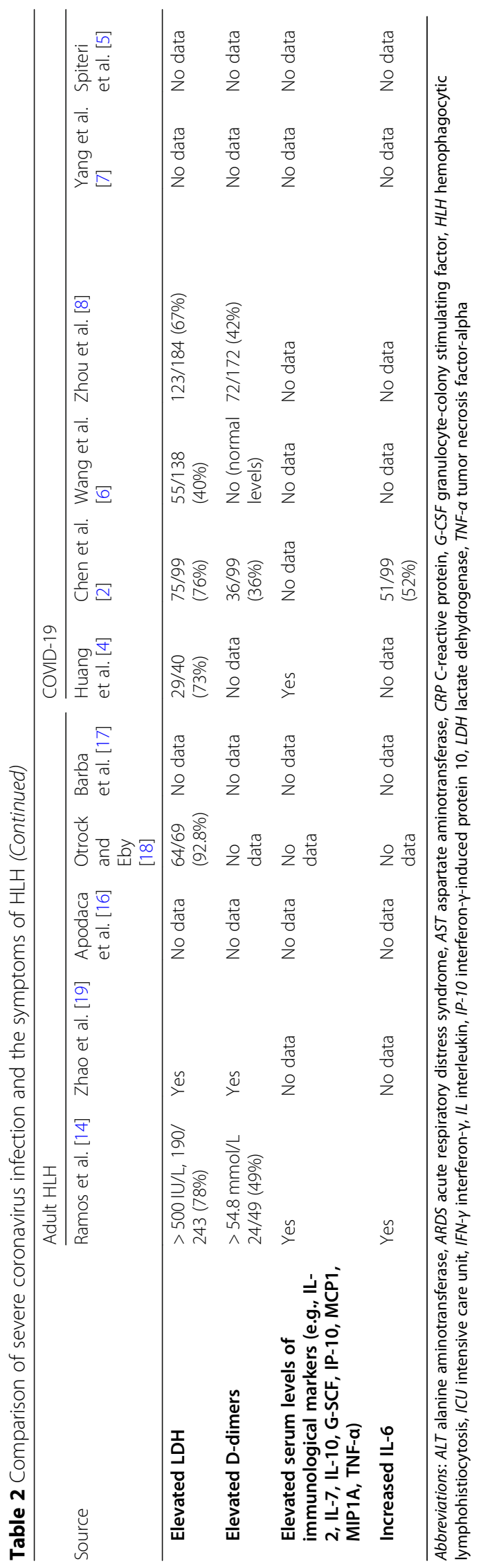


reactants (i.e., erythrocyte sedimentation rate or Creactive protein [CRP] concentration) are identified in $62-90 \%$ of patients $[14,17]$. Moreover, $90-100 \%$ of adult sHLH patients show increased ferritin concentrations (due to increased secretion of ferritin by macrophages or hepatocytes) $[14,16,18,19]$. Finally, high serum concentrations of soluble CD25 (interleukin [IL]-2 receptor- $\alpha$ ) occur in $77-79 \%$ of adult cases of sHLH [14, 18], although only very high levels of soluble CD25 are specific to HLH [23]. Other markers of macrophage activation (e.g., $\beta_{2}$-microglobulin) and cytokines (e.g., interferon $[$ IFN]- $\gamma$, TNF- $\alpha$ ) are also elevated in HLH [14].

Similar to SHLH, COVID-19 patients present with several laboratory abnormalities, with severe cases showing more prominent abnormalities (i.e., lymphocytopenia, thrombocytopenia, elevated CRP levels) than non-severe cases [24]. Elevated D-dimer, serum ferritin, LDH, and IL-6 levels were also shown throughout the clinical course of non-surviving patients with SARS-CoV-2 pneumonia compared with survivors [8]. In a series of 1449 hospitalized subjects with COVID-19, baseline and maximum values of prothrombin time, activated partial thromboplastin time, and D-dimer levels were significantly higher in subjects who died than in survivors [24]. Subjects who died had higher fibrinogen concentrations at baseline, but lower minimum values, than survivors [24]. Baseline D-dimer levels and the difference in fibrinogen and platelet levels correlated with an increased risk of death among patients with COVID-19 [24]. Indeed, other observations confirm the relationship between coagulation disorders and prognosis [6, 25, 26].

Coagulation disorders are reported in patients with sHLH, frequently with decreased fibrinogen levels, and can result in severe bleeding complications [27]. Indeed, a low fibrinogen level is one of the main HLH diagnostic criteria [22]. Although this process in HLH is not fully explained, the release of proinflammatory cytokines can cause the release of tissue plasminogen activator and the activation of an alternative fibrinolytic pathway in macrophages [27]. These factors can result in severe consumptive coagulopathy, with elevated fibrinogen degradation and decreased fibrinogen levels. Additionally, liver dysfunction may exacerbate coagulopathy [27]. Therefore, the increase in proinflammatory cytokine release in COVID19 may lead to analogous coagulation disorders in these patients. Indeed, the abovementioned laboratory abnormalities suggest that a hyper-inflammatory reaction is occurring in patients with severe COVID-19.

\section{Does SARS-CoV-2 trigger a cytokine storm syndrome?}

Due to the clinical similarities between severe cases of COVID-19 and SHLH, it has been postulated that SARSCoV-2 may be a trigger for a cytokine storm syndrome, like sHLH [28]. Indeed, previous studies have shown the poor outcomes of patients severe acute respiratory syndrome (SARS) and Middle East respiratory syndrome (MERS), which are caused by SARS-CoV and MERS$\mathrm{CoV}$, respectively, are associated with high levels of proinflammatory cytokines (e.g., IL-1 $\beta$ ) in the lower respiratory tract and other tissues [29]. The high expression of IL-1 $\beta$ in these tissues further promotes the expression of other proinflammatory cytokines (e.g., TNF- $\alpha$ and IL-6), resulting in a cytokine storm [30]. For example, activation of NF- $\mathrm{KB}$ has been shown to contribute to the inflammation induced after SARS-CoV infection [31]. Similarly, SARS-CoV-2 may trigger $\mathrm{sHLH}$ or a related inflammatory syndrome in some patients.

A recent retrospective, multicenter study of 150 confirmed COVID-19 cases in Wuhan, China, reported poor outcomes of patients with elevated ferritin and IL-6, suggesting virally driven hyperinflammation may be associated with mortality [32]. Furthermore, Huang et al. recently reported a cytokine profile resembling $\mathrm{sHLH}$ (characterized by increased IL-2, IL-7, granulocyte colony-stimulating factor [G-CSF], IFN- $\gamma$-induced protein 10 [IP-10], monocyte chemo-attractant protein 1 [MCP-1], macrophage inflammatory protein [MIP] 1- $\alpha$, and TNF- $\alpha$ ) is associated with the severity of COVID-19 [4]. In particular, IL-6 is thought to contribute to the progression of COVID-19 patients to severe ARDS [33]. A more detailed analysis of the literature has uncovered many similarities between the characteristics observed in severe cases COVID-19 infection and SHLH (as summarized in Table 2). For example, serum ferritin and CRP levels are above the normal range (i.e., in $63-80 \%$ and $61-86 \%$ of patients, respectively) in patients with severe COVID-19 infection, which is also observed in sHLH [2]. Furthermore, patients with severe COVID-19 infections have been shown to rapidly develop a number of complications, which resemble the multi-organ failure that arises in HLH.

\section{Severe COVID-19 shows rapid progression similar to HLH}

A characteristic feature of severe COVID-19 is that disease progresses rapidly, and the patient develops multiorgan failure in a short period of time [2]. As is observed in cases of HLH $[14,16,17,19]$, patients with severe COVID-19 show rapid signs of multi-organ damage. For example, among 99 patients diagnosed with SARS-CoV2 pneumonia, 17\% developed ARDS, $8 \%$ developed acute respiratory injury, 3\% developed acute renal injury, and $4 \%$ progressed to septic shock [2]. In addition, among 52 critically ill patients with SARS-CoV-2 pneumonia, 67\% had ARDS, 29\% had acute renal injury, 23\% had cardiac injury, 29\% had liver dysfunction, and $2 \%$ had pneumothorax [7]. In another retrospective, single-center case series of 138 consecutive hospitalized patients with confirmed SARS-CoV-2 pneumonia, 8.7\% developed septic 
shock, 19.6\% developed ARDS, 16.7\% had arrhythmias, and $7.2 \%$ had acute cardiac injury [6]. In a retrospective, multi-center cohort including 191 adult inpatients with laboratory-confirmed COVID-19, sepsis was the most frequently observed complication (observed in 59\% of cases), followed by respiratory failure (54\%), ARDS (31\%), heart failure (23\%), and then septic shock (20\%) [8]. In terms of the times of onset for the various complications arising from COVID-19, sepsis is reported to develop a median of 9 days after illness onset, followed by ARDS (12 days), acute cardiac injury (15 days), acute renal injury (15 days), and then secondary infection (17 days) [8]. As COVID-19 follows a similar pathogenesis to sHLH, early diagnosis and prompt immunosuppression is key, before such multi-organ failure sets in [34].

\section{Diagnosing HLH in patients with COVID-19}

The diagnosis of sHLH is based on clinical symptoms and results of diagnostic tests. According to the revised HLH2004 guideline [35], which was recently updated for adult patients [36], the diagnosis is based on five criteria (fever, splenomegaly, bicytopenia, hypertriglyceridemia and/or hypofibrinogenemia, and hemophagocytosis) and three additional criteria: low/absent NK-cell-activity, hyperferritinemia, and high-soluble IL-2-receptor levels. Other abnormal clinical and laboratory findings consistent with the diagnosis are cerebromeningeal symptoms, lymph node enlargement, jaundice, edema, skin rash, hepatic enzyme abnormalities, hypoproteinemia, hyponatremia, VLDL increase, and HDL decrease. Five of these eight criteria must be fulfilled, unless family history or molecular diagnosis is consistent with HLH. Absence of hemophagocytosis does not exclude a diagnosis [35]. Nonetheless, a simple score for the diagnosis of HLH is freely available online, named the Hscore [37]. The problem is that these criteria mainly correspond to primary HLH, not always to sHLH [38]. For example, the macrophage activation syndrome (MAS) - sHLH associated with autoimmune diseases is diagnosed based on other criteria: i.e., thrombocytopenia, hypofibrinogenemia, hypertriglyceridemia with other cutoff values, and high aspartate aminotransferase (AST) levels, which are included in the HLH-2004 criteria [38]. Therefore, it is likely that a different set of criteria would be needed to diagnose SHLH associated with COVID-19 [39]. Nevertheless, based on current evidence, sHLH should be suspected in patients with worsening or severe COVID-19, and early diagnosis could potentially be made using a panel of diagnostic tests based on the Hscore (see Fig. 1).

It is also important to mention that HLH presents with similar characteristics to other inflammatory disorders, such as sepsis, septic shock, and cytokine release syndrome (CRS) [22]. Sepsis is a life-threatening organ dysfunction caused by a dysregulated host response to infection and is diagnosed according to a suspected or documented infection and an acute increase of $\geq 2$ SOFA (Sequential [Sepsis-Related] Organ Failure Assessment Score) points (a proxy for organ dysfunction [38]). Septic shock is a subset of sepsis, in which underlying circulatory and cellular or metabolic abnormalities substantially increase mortality.

Unfortunately, the current criteria do not allow a clear differentiation of sepsis from HLH, and it is proposed that sepsis and HLH may have a common mechanism, whereby systemic immune dysregulation is triggered by a specific external agent [14]. CRS is another systemic inflammatory response that can be triggered by infections and can present with similar symptoms (e.g., fever, fatigue, headache, rash, arthralgia, myalgia, uncontrolled systemic inflammatory response, and multi-organ failure) and laboratory abnormalities (e.g., cytopenias, elevated creatinine and liver enzymes, abnormal coagulation parameters, and high CRP levels) to HLH [40]. Respiratory symptoms are also common in patients with CRS, including ARDS, as well as renal failure or cardiac dysfunction [40]. Therefore, the diagnosis of HLH is complicated due to the nonspecific clinical manifestations and laboratory findings associated with this condition [15], and more precise criteria should be developed in the future.

\section{How can an early diagnosis of HLH help in the management of COVID-19?}

To date, no effective clinical management has been established for COVID-19 and there is no evidence for specific drug treatment against SARS-Cov-2 in suspected or confirmed cases [36].

For diagnosis and ongoing management of COVID-19, lung imaging (X-ray, computed tomography) and laboratory tests are recommended [41]. Laboratory tests include a throat swab or other respiratory sampling to identify SARS-CoV-2 RNA by PCR; hematology examination (blood count, lymphocyte subpopulation); tests for common respiratory viruses, mycoplasma, chlamydia, and tuberculosis; liver and renal function tests; myocardial enzyme and myoglobin levels; erythrocyte sedimentation rate; CRP, procalcitonin, lactate, and D-dimer levels; coagulation image; a routine urine test; measurement of inflammatory factors (IL-6, IL-10, TNF- $\alpha$ ), complement; and anti-acid staining [41] These parameters should be constantly monitored in patients with COVID-19. Adding ferritin, fibrinogen, triglycerides, total protein/albumin, and lactate dehydrogenase to laboratory tests would allow early identification of patients with a cytokine storm syndrome like sHLH.

Effective management of COVID-19 would require either prevention (i.e., a vaccine) or, in the case of infection, specific antiviral treatments and inhibitors of generalized inflammation. Moreover, whether treating 


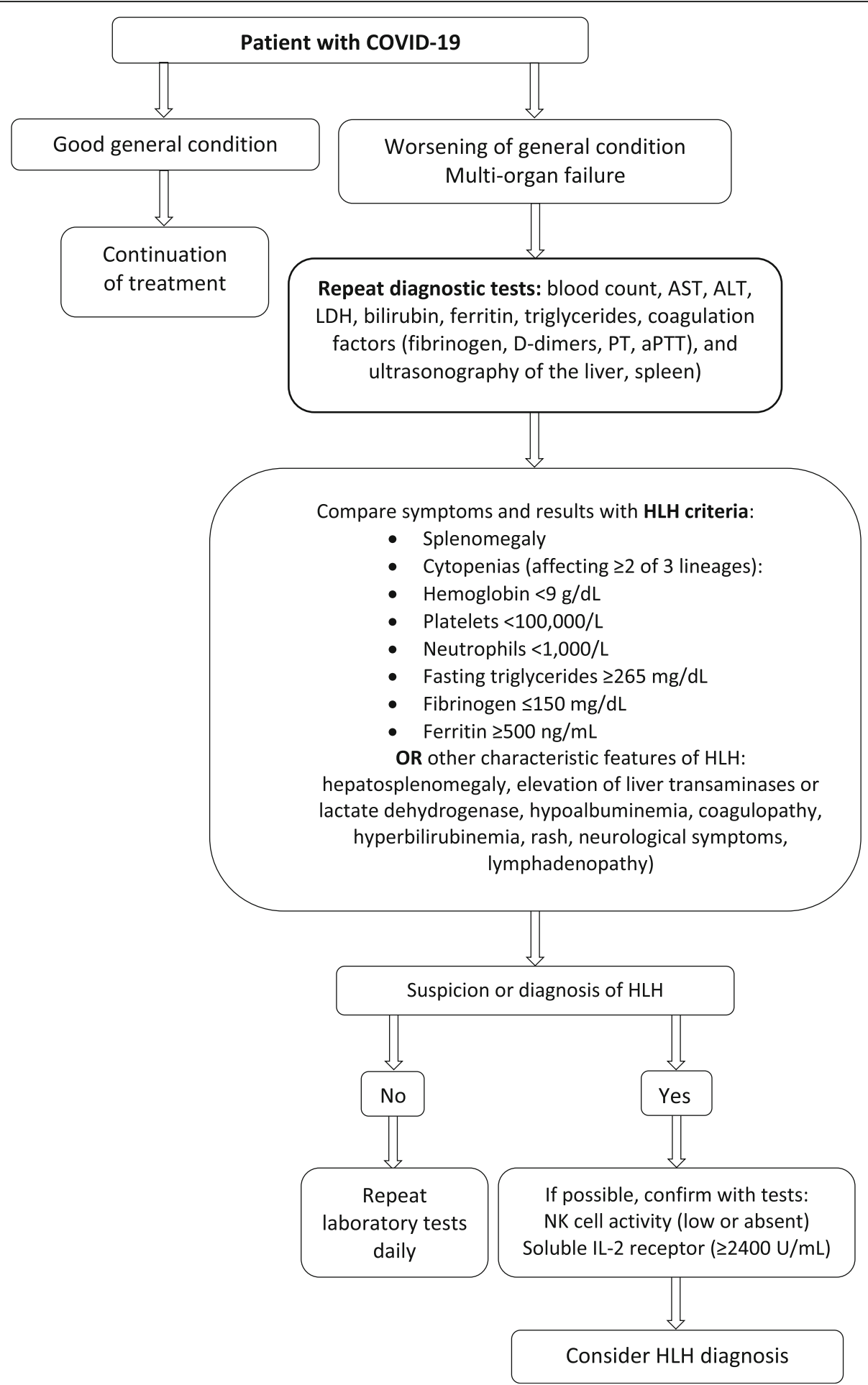

Fig. 1 Proposed diagnostic scheme for patients with COVID-19. Abbreviations: ALT, alanine aminotransferase; AST, aspartate aminotransferase; COVID-19, coronavirus disease 2019; HLH, hemophagocytic lymphohistiocytosis; IL-2, interleukin-2; LDH, lactate dehydrogenase; NK, natural killer; PT, prothrombin time; aPPT, activated partial thromboplastin time

sHLH in the course of COVID-19 improves patients outcomes requires further study. Nonetheless, if a diagnosis of sHLH were to be made in patients with
COVID-19, it would be beneficial to control the hyperinflammatory reaction that leads to multi-organ failure and death. Although HLH management is based on the 
HLH-2004 guidelines [22] (which were recently updated for adult patients [36]), the treatment should be modified based on the underlying cause and course of the disease [42]. It is certain that the effectiveness of the therapy is time-dependent; therefore, HLH therapy should be started as soon as possible, preferably on the day of diagnosis [22]. The aim of the initial treatment is to control the hyperactivated immune system. A corticosteroid is usually selected as the first-line treatment, preferably dexamethasone. However, in cases of infection-associated HLH, a high-dose intravenous immunoglobulin (IVIG) is often used for the initial treatment, plasma exchange or exchange transfusion may also be performed to eliminate cytokines and improve the coagulation state $[22,42]$. Despite these chemoimmunotherapy recommendations, in EBV-associated HLH (EBV-HLH), some patients may be cured with corticosteroid treatment alone [43]. Furthermore, patients with an infection-associated HLH other than EBV-HLH often enter remission when they are treated with corticosteroids, IVIG, and/or cyclosporine in addition to the treatment for the infectious disease [42]. However, once again, the effectiveness of this treatment relies on the early inclusion of treatment. Therefore, we propose patients with worsening or severe COVID-19 should undergo a diagnostic panel of tests (shown in Fig. 1) and constant monitoring to enable rapid intervention of appropriate treatment.

\section{Controlling the COVID-19 cytokine storm: experimental therapies}

In addition to the HLH-2004 protocol, an anti-IL-6 antibody (tocilizumab) was FDA-approved in 2014 for HLH patients aged $\geq 2$ years, as it results in rapid resolution of cytokine release syndrome in patients after chimeric antigen receptor (CAR) $\mathrm{T}$ cell or blinatumomab treatment [36]. In 2018, a CAR T cell-associated toxicity working group suggested suspected HLH should be managed with anti-IL-6 therapy as well as corticosteroids for those with organ toxicities $\geq$ grade $3[36,44]$. Encouragingly, the recently announced COVACTA trial aims to evaluate the safety and efficacy of intravenous tocilizumab in hospitalized adult patients with severe COVID-19 pneumonia (ClinicalTrials.gov Identifier: NCT04320615) [45], and a multicenter, randomized controlled trial of tocilizumab has been approved in patients with COVID-19 pneumonia and elevated IL-6 2 in China (Chinese Clinical Trial Registry: ChiCTR2000029765) [46]. In addition, IL-1 blockade with anakinra has shown a significant survival benefit in patients with hyperinflammation [47]. Thus, a clinical study to evaluate the efficacy and safety of anakinra and emapalumab (an anti-IFN- $\gamma$ antibody that is FDAapproved for adult and pediatric patients with primary $\mathrm{HLH}$ ) in the treatment of hyperinflammatory syndrome associated with severe cases of COVID-19 is currently underway (ClinicalTrials.gov Identifier: NCT04324021) [48].

Janus kinase (JAK) inhibition is another therapeutic strategy, which could affect both inflammation and cellular viral entry in cases of COVID-19 [49]. Activation of the NF- $\mathrm{kB}$ (nuclear factor kappa B) signaling pathway was also shown to contribute to the inflammation induced after SARS-CoV-1 infection [31]; therefore, NF$\kappa B$ inhibitors may be promising for the treatment of severe COVID-19. Thus, there are a number of exciting new therapies in the pipeline to combat severe cases of COVID-19.

\section{Conclusion}

SARS-CoV-2 is also a novel human pathogen that may interact with host antiviral defense in a unique manner. Severe cases of COVID-19 share a number of clinical characteristics with HLH. Without early diagnosis and prompt appropriate treatment, the mortality rate of HLH is very high [13]. Therefore, it is recommended all patients with severe COVID-19 should be screened for hyperinflammation using standard laboratory tests and the HScore [35] to identify the subgroups of patients for whom immunosuppressive therapy may improve outcomes. We acknowledge that a different set of criteria may be required to diagnose patients with COVID-19associated HLH [39]. Management by a multidisciplinary team of experts (including hemato-oncologists, immunologists, rheumatologists, and intensivists) will be required to provide patients with access to such a full range of treatment options.

\section{Abbreviations}

ALT: Alanine aminotransferase; AST: Aspartate aminotransferase; ARDS: Acute respiratory distress syndrome; COVID-19: Coronavirus disease 2019; CRP: Creactive protein; CRS: Cytokine release syndrome; G-CS: Granulocyte-colony stimulating factor; HLH: Hemophagocytic lymphohistiocytosis; Hscore: Score for the diagnosis of HLH; IFN- $\gamma$ : Interferon- $\gamma ;$ IL : Interleukin; IP-10: Interferon$\gamma$-induced protein 10; JAK: Janus kinase; LDH: Lactate dehydrogenase; MAS: Macrophage activation syndrome; MERS: Middle East respiratory syndrome; MCP-1: Monocyte chemo-attractant protein 1; MIP: Macrophage inflammatory protein; NK: Natural killer; NF-kB: Nuclear factor kappa B; PT: Prothrombin time; aPPT: Activated partial thromboplastin time; SARS: Severe acute respiratory syndrome; SARS-CoV-2: Severe acute respiratory syndrome coronavirus 2; sHLH: Secondary hemophagocytic lymphohistiocytosis; SOFA: Sequential [Sepsis-Related] Organ Failure Assessment Score; TNF-a: Tumor necrosis factor-alpha

\section{Acknowledgements}

Not applicable

\section{Authors' contributions}

All of the authors contributed substantially to the preparation of this review and met the authorship criteria according to the International Committee of Medical Journal Editors (IMCJE) guidelines. All authors have read and agreed to the published version of the manuscript.

\section{Funding}

This work was supported by the Polish National Science Center (grant no. UMO-2016/21/B/NZ6/02279) and the Medical University of Lublin (grants no. DS460 and DS461). 


\section{Availability of data and materials}

Not applicable

\section{Ethics approval and consent to participate \\ Not applicable}

\section{Consent for publication}

Not applicable

\section{Competing interests}

The authors declare no competing interests.

\section{Author details}

'Department of Paediatric Pulmonology and Rheumatology, Medical University of Lublin, Gębali 6, 20-093 Lublin, Poland. ²Department of Clinical Immunology and Immunotherapy, Medical University of Lublin, Chodzki 4a Street, 20-093 Lublin, Poland. 'Department of Clinical Immunology, St. John's Cancer Hospital, K. Jaczewskiego 7 St, 20-090 Lublin, Poland.

\section{Received: 17 April 2020 Accepted: 25 June 2020}

\section{Published online: 15 July 2020}

\section{References}

1. Coronavirus disease (COVID-19) Pandemic [https://www.who.int/ emergencies/diseases/novel-coronavirus-2019]. Accessed 23 June 2020.

2. Chen N, Zhou M, Dong X, Qu J, Gong F, Han Y, Qiu Y, Wang J, Liu Y, Wei Y, et al. Epidemiological and clinical characteristics of 99 cases of 2019 novel coronavirus pneumonia in Wuhan, China: a descriptive study. Lancet. 2020; 395(10223):507-13.

3. Guan W-J, Ni Z-Y, Hu Y, Liang W-H, Ou C-Q, He J-X, Liu L, Shan H, Lei C-L, DSC H, et al. Clinical characteristics of coronavirus disease 2019 in China. N Engl J Med. 2020;382:1708-1720. https://doi.org/10.1056/NEJMoa2002032.

4. Huang C, Wang Y, Li X, Ren L, Zhao J, Hu Y, Zhang L, Fan G, Xu J, Gu X, et al. Clinical features of patients infected with 2019 novel coronavirus in Wuhan, China. Lancet. 2020:395(10223):497-506.

5. Spiteri G, Fielding J, Diercke M, Campese C, Enouf V, Gaymard A, Bella A, Sognamiglio P, Sierra Moros MJ, Riutort AN, et al. First cases of coronavirus disease 2019 (COVID-19) in the WHO European Region, 24 January to 21 February 2020. Euro Surveill. 2020;25(9):2000178.

6. Wang D, Hu B, Hu C, Zhu F, Liu X, Zhang J, Wang B, Xiang H, Cheng Z, Xiong Y, et al. Clinical characteristics of 138 hospitalized patients with 2019 novel coronavirus-infected pneumonia in Wuhan, China. JAMA. 2020; 323(11):1061-9.

7. Yang $X, Y u$ Y, Xu J, Shu H, Xia JA, Liu H, Wu Y, Zhang L, Yu Z, Fang $M$ et al. Clinical course and outcomes of critically ill patients with SARS-CoV-2 pneumonia in Wuhan, China: a single-centered, retrospective, observational study. Lancet Respir Med. 2020;8:475-81. https://doi.org/10.1016/S22132600(20)30079-5

8. Zhou F, Yu T, Du R, Fan G, Liu Y, Liu Z, Xiang J, Wang Y, Song B, Gu X, et al. Clinical course and risk factors for mortality of adult inpatients with COVID19 in Wuhan, China: a retrospective cohort study. Lancet. 2020;395(10229): 1054-62.

9. Fung S-Y, Yuen K-S, Ye Z-W, Chan C-P, Jin D-Y. A tug-of-war between severe acute respiratory syndrome coronavirus 2 and host antiviral defence: lessons from other pathogenic viruses. Emerging Microbes Infections. 2020;9(1):558-70.

10. Guo YR, Cao QD, Hong ZS, Tan YY, Chen SD, Jin HJ, Tan KS, Wang DY, Yan Y. The origin, transmission and clinical therapies on coronavirus disease 2019 (COVID-19) outbreak - an update on the status. Mil Med Res. 2020;7(1):11.

11. Janka GE. Familial and acquired hemophagocytic lymphohistiocytosis. Annu Rev Med. 2012;63:233-46.

12. Marsh RA. Epstein-Barr virus and hemophagocytic lymphohistiocytosis. Front Immunol. 2018:8:1902.

13. Dropulic LK, Cohen J. Severe viral infections and primary immunodeficiencies. Clin Infect Dis. 2011;53(9):897-909.

14. Ramos-Casals M, Brito-Zerón P, López-Guillermo A, Khamashta MA, Bosch X. Adult haemophagocytic syndrome. Lancet. 2014;383(9927):1503-16.

15. Han X-C, Ye Q, Zhang W-Y, Tang Y-M, Xu X-J, Zhang T. Cytokine profiles as novel diagnostic markers of Epstein-Barr virus-associated hemophagocytic lymphohistiocytosis in children. J Crit Care. 2017;39:72-7.

16. Apodaca E, Rodriguez-Rodriguez S, Tuna-Aguilar EJ, Demichelis-Gomez R. Prognostic factors and outcomes in adults with secondary hemophagocytic lymphohistiocytosis: a single-center experience. Clin Lymphoma Myeloma Leuk. 2018;18(10):e373-80.

17. Barba T, Maucort-Boulch D, Iwaz J, Bohe J, Ninet J, Hot A, Lega JC, Guerin C, Argaud L, Broussolle C, et al. Hemophagocytic lymphohistiocytosis in intensive care unit: a 71-case strobe-compliant retrospective study. Medicine (Baltimore). 2015:94(51):e2318.

18. Otrock ZK, Eby CS. Clinical characteristics, prognostic factors, and outcomes of adult patients with hemophagocytic lymphohistiocytosis. Am J Hematol. 2015:90(3):220-4.

19. Zhao Y, Lu D, Ma S, Li L, Zhu J, Zhou, Zheng Y, Yang X, Zhu L, Zhu M, et al. Risk factors of early death in adult patients with secondary hemophagocytic lymphohistiocytosis: a single-institution study of 171 Chinese patients. Hematology. 2019;24(1):606-12.

20. Usmani GN, Woda BA, Newburger PE. Advances in understanding the pathogenesis of HLH. Br J Haematol. 2013;161(5):609-22.

21. Seguin A, Galicier L, Boutboul D, Lemiale V, Azoulay E. Pulmonary involvement in patients with hemophagocytic lymphohistiocytosis. Chest. 2016;149(5):1294-301.

22. Henter J-I, Horne A, Aricó M, Egeler RM, Filipovich AH, Imashuku S, Ladisch S, McClain K, Webb D, Winiarski J, et al. HLH-2004: diagnostic and therapeutic guidelines for hemophagocytic lymphohistiocytosis. Pediatr Blood Cancer. 2007;48(2):124-31.

23. Hayden A, Lin M, Park S, Pudek M, Schneider M, Jordan MB, Mattman A, Chen LYC. Soluble interleukin-2 receptor is a sensitive diagnostic test in adult HLH. Blood Advances. 2017;1(26):2529-34. https://doi.org/10.1038/ s41375-020-0910-1.

24. Li Q, Cao Y, Chen L, Wu D, Yu J, Wang H, He W, Chen L, Dong F, Chen W, et al. Hematological features of persons with COVID-19. Leukemia. 2020.

25. Rodelo JR, De la Rosa G, Valencia ML, Ospina S, Arango CM, Gómez Cl, García A, Nuñez E, Jaimes FA. D-dimer is a significant prognostic factor in patients with suspected infection and sepsis. Am J Emerg Med. 2012;30(9): 1991-9.

26. Tang N, Li D, Wang X, Sun Z. Abnormal coagulation parameters are associated with poor prognosis in patients with novel coronavirus pneumonia. J Thromb Haemost. 2020;18(4):844-7.

27. Valade S, Mariotte E, Azoulay E. Coagulation disorders in hemophagocytic lymphohistiocytosis/macrophage activation syndrome. Crit Care Clin. 2020; 36(2):415-26.

28. Mehta P, McAuley DF, Brown M, Sanchez E, Tattersall RS, Manson JJ. COVID19: consider cytokine storm syndromes and immunosuppression. Lancet. 2020;395(10229):1033-4

29. He L, Ding Y, Zhang Q, Che X, He Y, Shen H, Wang H, Li Z, Zhao L, Geng J, et al. Expression of elevated levels of pro-inflammatory cytokines in SARSCoV-infected ACE2+ cells in SARS patients: relation to the acute lung injury and pathogenesis of SARS. J Pathol. 2006;210(3):288-97.

30. Nieto-Torres JL, DeDiego ML, Verdiá-Báguena C, Jimenez-Guardeño JM, Regla-Nava JA, Fernandez-Delgado R, Castaño-Rodriguez C, Alcaraz A, Torres J, Aguilella VM, et al. Severe acute respiratory syndrome coronavirus envelope protein ion channel activity promotes virus fitness and pathogenesis. PLoS Pathog. 2014;10(5):e1004077

31. DeDiego ML, Nieto-Torres JL, Regla-Nava JA, Jimenez-Guardeño JM Fernandez-Delgado R, Fett C, Castaño-Rodriguez C, Perlman S, Enjuanes L. Inhibition of NF-kB-mediated inflammation in severe acute respiratory syndrome coronavirus-infected mice increases survival. J Virol. 2014;88(2): 913-24.

32. Ruan Q, Yang K, Wang W, Jiang L, Song J. Clinical predictors of mortality due to COVID-19 based on an analysis of data of 150 patients from Wuhan, China. Intensive Care Medicine. 2020;46(5):846-8. https://doi.org/10.1007/ s00134-020-05991-x

33. Chen $C$, Zhang XR, Ju ZY, He WF. Advances in the research of cytokine storm mechanism induced by corona virus disease 2019 and the corresponding immunotherapies. Zhonghua Shao Shang Za Zhi. 2020;36(0): E005

34. Ramachandran S, Zaidi F, Aggarwal A, Gera R. Recent advances in diagnostic and therapeutic guidelines for primary and secondary Hemophagocytic lymphohistiocytosis. Blood Cell Mol Dis. 2017:64:53-57. https://doi.org/10.1016/j.bcmd.2016.10.023.

35. Fardet L, Galicier L, Lambotte O, Marzac C, Aumont C, Chahwan D, Coppo P, Hejblum G. Development and validation of the HScore, a score for the diagnosis of reactive hemophagocytic syndrome. Arthritis Rheumatol. 2014: 66(9):2613-20. 
36. La Rosée P, Horne A, Hines M, von Bahr GT, Machowicz R, Berliner N, Birndt S, Gil-Herrera J, Girschikofsky M, Jordan MB, et al. Recommendations for the management of hemophagocytic lymphohistiocytosis in adults. Blood. 2019:133(23):2465-77.

37. Hscore [http://saintantoine.aphp.fr/score/]. Accessed 23 June 2020.

38. Singer M, Deutschman CS, Seymour CW, Shankar-Hari M, Annane D, Bauer M, Bellomo R, Bernard GR, Chiche J-D, Coopersmith CM, et al. The third international consensus definitions for sepsis and septic shock (Sepsis-3). JAMA. 2016;315(8):801-10.

39. Mehta P, Cron RQ, Hartwell J, Manson JJ, Tattersall RS. Silencing the cytokine storm: the use of intravenous anakinra in haemophagocytic lymphohistiocytosis or macrophage activation syndrome. Lancet Rheumatol. 2020;2(6):e358-67.

40. Shimabukuro-Vornhagen A, Gödel P, Subklewe M, Stemmler HJ, Schlößer HA, Schlaak M, Kochanek M, Böll B, von Bergwelt-Baildon MS. Cytokine release syndrome. J ImmunoTherapy Cancer. 2018;6(1):56.

41. Jin Y-H, Cai L, Cheng Z-S, Cheng H, Deng T, Fan Y-P, Fang C, Huang D, Huang L-Q, Huang Q, et al. A rapid advice guideline for the diagnosis and treatment of 2019 novel coronavirus (2019-nCoV) infected pneumonia (standard version). Military Med Res. 2020;7(1):4.

42. Morimoto A, Nakazawa Y, Ishii E. Hemophagocytic lymphohistiocytosis: pathogenesis, diagnosis, and management. Pediatr Int. 2016;58(9):817-25.

43. Shiraishi A, Ohga S, Doi T, Ishimura M, Takimoto T, Takada H, Miyamoto T, Abe Y, Hara T. Treatment choice of immunotherapy or further chemotherapy for Epstein-Barr virus-associated hemophagocytic lymphohistiocytosis. Pediatr Blood Cancer. 2012;59(2):265-70.

44. Neelapu SS, Tummala S, Kebriaei P, Wierda W, Gutierrez C, Locke FL, Komanduri KV, Lin Y, Jain N, Daver N, et al. Chimeric antigen receptor T-cell therapy - assessment and management of toxicities. Nat Rev Clin Oncol. 2018;15(1):47-62.

45. A study to evaluate the safety and efficacy of tocilizumab in patients with severe COVID-19 pneumonia (COVACTA). ClinicalTrials.gov Identifier: NCT04320615 [https://clinicaltrials.gov/ct2/show/NCT04320615]. Accessed 23 June 2020.

46. A multicenter, randomized controlled trial for the efficacy and safety of tocilizumab in the treatment of new coronavirus pneumonia (COVID-19). Chinese Clinical Trial Registry: ChiCTR2000029765 [http://www.chictr.org.cn/ showprojen.aspx?proj=49409]. Accessed 23 June 2020.

47. Shakoory B, Carcillo J, Chatham W, Amdur R, Zhao H, Dinarello C, Cron R, Opal $\mathrm{S}$. Interleukin-1 receptor blockade is associated with reduced mortality in sepsis patients with features of macrophage activation syndrome. Crit Care Med. 2015;44:1.

48. Efficacy and safety of emapalumab and anakinra in reducing hyperinflammation and respiratory distress in patients with COVID-19 infection. ClinicalTrials.gov Identifier: NCT04324021 [https://clinicaltrials.gov/ ct2/show/NCT04324021]. Accessed 23 June 2020.

49. Richardson P, Griffin I, Tucker C, Smith D, Oechsle O, Phelan A, Stebbing J. Baricitinib as potential treatment for 2019-nCoV acute respiratory disease. Lancet. 2020;395(10223):e30-1.

\section{Publisher's Note}

Springer Nature remains neutral with regard to jurisdictional claims in published maps and institutional affiliations.

Ready to submit your research? Choose BMC and benefit from:

- fast, convenient online submission

- thorough peer review by experienced researchers in your field

- rapid publication on acceptance

- support for research data, including large and complex data types

- gold Open Access which fosters wider collaboration and increased citations

- maximum visibility for your research: over $100 \mathrm{M}$ website views per year

At BMC, research is always in progress.

Learn more biomedcentral.com/submissions 